\title{
Liver transplantation for rare liver diseases and rare indications for liver transplant
}

\author{
Michele Finotti", Pasquale Auricchio", Alessandro Vitale, Enrico Gringeri", Umberto Cillo" \\ Department of Surgery, Oncology and Gastroenterology, Hepatobiliary Surgery and Liver Transplantation Unit, Padova University Hospital, \\ Padova, Italy \\ Contributions: (I) Conception and design: All authors; (II) Administrative support: All authors; (III) Provision of study materials or patients: None; \\ (IV) Collection and assembly of data: All authors; (V) Data analysis and interpretation: All authors; (VI) Manuscript writing: All authors; (VII) Final \\ approval of manuscript: All authors. \\ \#These authors contributed equally to this work. \\ Correspondence to: Alessandro Vitale. Department of Surgery, Oncology and Gastroenterology, University of Padua, Via Giustiniani 2, 35128 Padova, \\ Italy. Email: alessandro.vitale@unipd.it.
}

\begin{abstract}
Liver transplantation (LT) is currently considered the gold standard treatment for end-stage liver failure. Compared to the first decades of its use, LT is associated with lower comorbidity and mortality, with a 5 -year survival over $70 \%$. Worldwide, liver cirrhosis and hepatocellular carcinoma represent the major indications to LT. However, almost $1 \%$ of LT is performed for rare diseases or rare indications, which include non-hepatocellular malignancy, vascular disorders, metabolic and congenital liver disorders. These diseases can lead to hepatocellular necrosis, biliary tree abnormality and/or hepatomegaly. Most of these diseases are not associated with liver failure but in highly selected patients, LT represent an effective therapy improving the overall survival and quality of life. Rare indications for LT often overlap with rare diseases. However, rare LT indications for non-rare diseases are rising in the last decades, especially for benign primary liver tumor, colon rectal liver metastasis, neuroendocrine liver metastasis, and cholangiocarcinoma (CCA). Non-rare diseases with rare indication for LT and rare adult disease with an indication for LT are categorized and discussed in detail, focusing on some disorders for which the literature provides a more definitive evidence base. Early referral to a transplant center is encouraged to provide an effective therapeutic option in these non-standard indications for LT.
\end{abstract}

Keywords: Rare indication; oncology transplantation; liver metastases; liver failure

Received: 14 October 2019. Accepted: 12 June 2020; Published: 05 April 2021.

doi: $10.21037 /$ tgh-19-282

View this article at: http://dx.doi.org/10.21037/tgh-19-282

\section{Introduction}

During the last 3 decades, liver transplantation (LT) has been the standard treatment for patients affected by liver failure. Nowadays, the 5-year survival rates after LT exceed $70 \%$, with lower comorbidity and mortality compared to the past. Judging from data in the European Liver Transplant Registry (ELTR) (1), a plateau in LTs seems to have been reached in the recent years, with about 7,300 LTs being performed in all of Europe annually. In contrast, data from between 1988 and 2018 from the United Network for
Organ Sharing (UNOS) Liver Transplant Registry indicate that liver transplants almost quintupled from 1,713 to 8,250 , continuing to slightly increase in the last few years (2).

In the ELTR area (1), the most frequent indication for LT was liver cirrhosis (50\%), with $22 \%$ of cases being related to viral infection (with a prevalence of hepatitis $\mathrm{C}$ virus (HCV) and cirrhosis) and 19\% being related to alcohol abuse. Primary liver tumors, predominantly hepatocellular carcinoma, represent $17 \%$ of LT indications, followed by cholestatic liver disease $[10 \%$, including primary biliary cirrhosis and primary sclerosing cholangitis (PSC)], and 
Table 1 Diseases leading to hepatocellular necrosis

\begin{tabular}{lc}
\hline Disease & Incidence \\
\hline Acute liver failure & $1-5 \times 10,000$ \\
Autoimmune hepatitis & $1-5 \times 10,000$ \\
Autosomal systemic lupus erythematosus & $1 \times 1,000,000$ \\
Classic galactosemia & $1 \times 40000$ \\
Hereditary fructose intolerance & $1-9 \times 100,000$ \\
Macrophage activation syndrome & n.d. \\
Neonatal hemochromatosis & $1 \times 100,000,000$ \\
Rare HH & n.d. \\
Tyrosinemia type 1 & $1 \times 100,000$ \\
Wilson disease & $1-9 \times 100,000$ \\
\hline
\end{tabular}

n.d., no data.

acute hepatic failure. Indications for LT are under $1 \%$ for some diseases like metabolic disorder (familial amyloidotic polyneuropathy, Wilson disease, alpha-1-antitrypsin deficiency), vascular disorders, Budd-Chiari syndrome (BCS), benign liver tumor, and secondary liver tumors (mainly neuroendocrine). Recently, unresectable colorectal liver metastases (CRLM) have garnered interest since the publication of the SECA trial by the University of Oslo (3).

From the last Organ Procurement and Transplantation Network/Scientific Registry of Transplant Recipients (OPTN/SRTR) 2017 Annual Data Report (4), 8082 liver transplants were performed in the United States. In the UNOS area, more than $30 \%$ of patients underwent LT for non-HCV and non-alcoholic related cirrhosis; nonalcoholic steatohepatitis (NASH) is a rapidly growing etiology of end-stage liver disease in the USA (5). Alcoholic liver disease ( $23 \%$ of LT), followed by primary liver tumors $(16 \%)$, especially hepatocellular carcinoma, are also growing LT indications. HCV-related liver disease has declined as indications in the last years, accounting for $12 \%$ of indications for LT.

Other indications are cholestatic liver disease (11\%), including primary biliary cholangitis and PSC; followed by idiopathic/autoimmune liver disease; acute liver failure (7\%); and hepatitis B virus (6\%). Meanwhile, the more rare indications are metabolic liver diseases, benign liver tumors, and secondary liver tumors.

Both in the ELTR and UNOS areas, rare indications for LT include non-hepatocellular malignancy, vascular disorders, and metabolic and congenital liver disorders. Most of these diseases are not associated with liver failure (hepatic synthetic dysfunction or portal hypertension), but LT represents an effective therapy providing a significant benefit in overall survival and quality of life for these patients.

Rare indications for LT often overlap with rare diseases. Exceptions to this rule (i.e., rare LT indications for nonrare diseases) cover some diseases in which LT is a rising indication: benign primary liver tumor, colon rectal liver metastasis, neuroendocrine liver metastasis, and CCA. These primary and secondary tumors have a medium-tohigh incidence in the population, but indication to LT is still rare and undergoing scientific validation. In this article, we will discuss the rare adult diseases with indication for LT and the non-rare diseases with rare indication for LT.

\section{Classification}

A disease is defined as rare when the incidence is below 1 per 10,000 . We here propose a classification based on the nature of the disease: non-neoplastic or neoplastic disease.

Furthermore, Tables 1,2,3, based on the Orphanet data propose a classification of the diseases according to the liver injury/alteration that leads to a potential indication for LT. In particular, some rare diseases can lead to: (I) hepatocellular necrosis; (II) biliary tree abnormality, leading to cholestasis; (III) hepatomegaly often resulting from metabolic/vascular dysfunction; (IV) other diseases with possible LT indication.

We will further focus on some disorders for which the literature provides a more definitive evidence base.

\section{Non-neoplastic diseases with possible indication for LT}

\section{Budd-Chiari}

BCS consists of hepatic venous outflow tract obstruction due to primary causes (thrombosis or phlebitis) or secondary causes (external compression or invasion of the hepatic veins and the vena cava).

According to the clinical manifestations, BCS can be categorized as (6,7): (I) acute liver failure, where jaundice, hepatic encephalopathy, elevation of transaminases, and prothrombin time and international normalized ratio (PT/INR) ratio worsen within a day; (II) acute, where the previous manifestations develops in weeks; (III) subacute, with minor signs presenting in months (8); (IV) chronic, associated with end stage liver disease. 
Table 2 Diseases leading to cholestatic jaundice

\begin{tabular}{lr}
\hline Disease & \multicolumn{1}{c}{ Incidence } \\
\hline Alagille syndrome & $1 \times 100,000$ \\
Alfa-1 antitrypsin & $1 \times 2,500$ \\
Biliary atresia with splenic malformation syndrome & $1-9 \times 1,000,000$ \\
Choledochal cyst & n.d. \\
Crigler-Najjar syndrome & $1-9 \times 10,000$ \\
Cystic fibrosis & $1-9 \times 100,000$ \\
Familial intrahepatic cholestasis & n.d. \\
Fulminant viral hepatitis & n.d \\
Hepatic fibrosis-renal cyst intellectual disability syndrome (Thompson-Baraitser syndrome) & $1 \times 1,000,000$ \\
Idiopathic ductopenia & n.d. \\
Isolated biliary atresia & $1-9 \times 100,000$ \\
Isolated congenital hepatic fibrosis & n.d \\
Primary biliary cholangitis & $1-5 \times 10,000$ \\
Rare tumor of the gallbladder and extrahepatic biliary tract & n.d. \\
Sclerosing cholangitis & n.d. \\
\hline
\end{tabular}

n.d., no data.

Table 3 Diseases leading to hepatomegaly

\begin{tabular}{lc}
\hline Disease & Incidence \\
\hline Beckwith-Wiedemann syndrome & $1-5 \times 10,000$ \\
Caroli disease & $1 \times 1,000,000$ \\
Congenital anomaly of hepatic vein & n.d. \\
Congenital portosystemic shunt & n.d. \\
Glycogen storage disease due to glucose-6-phosphatase deficiency & $1 \times 100,000$ \\
Glycogen storage disease due to glycogen-branching enzyme deficiency & n.d. \\
Hepatic veno-occlusive disease & $1-5 \times 10,000$ \\
Isolated PLD & $1 \times 1,000,000$ \\
Langerhans cell histiocytosis & $1-9 \times 100,000$ \\
BCS & $1-9 \times 100,000$ \\
Nodular regenerative hyperplasia of the liver & n.d. \\
\hline
\end{tabular}

n.d., no data.

An initial evaluation can be made with doppler ultrasonography and computed tomography (CT) scan, but venography is still considered the gold standard for definitive diagnosis. A sulfur-colloid scintigraphy is an alternative option to confirm the diagnosis (6). The treatment is tailored according to the underlying cause: thrombolysis, angioplasty/stenting, and medical treatments of portal hypertension.

LT should be considered when first-line treatments do not succeed or in the case of advanced cirrhosis. 
Patients undergoing LT have a chance to survive according to model for end-stage liver disease (MELD) score: the higher the MELD score is, the worse the outcome $(9,10)$. LT for BCS in the pre-MELD era compared to MELD era showed a worse 3-year graft (81\% vs. $65 \%)$ and patient survival (85\% vs. $73 \%)$ (11).

Mentha et al.'s study of a cohort of 248 patients transplanted for BCS reported an overall survival (OS) of $71 \%$ after 5 years and $68 \%$ after 10 years; the highest mortality rate occurred within the first 3 months after LT, especially in the patients with impaired renal function and previous shunt (9). Meanwhile, other studies suggest that patients affected with BCS have higher risk of vascular complications after LT (10).

\section{Caroli disease}

Caroli disease is a congenital disorder characterized by multifocal, segmental dilatation of large intrahepatic bile ducts (12) and is often associated with renal cystic disease. There are two variants of the disease: Caroli disease (a rare form with bile ductular ectasia) and Caroli syndrome (a more common form, associated with congenital hepatic fibrosis).

Caroli disease and syndrome may be parts of more complex diseases, including nephronophthisis, MeckelGruber syndrome, COACH syndrome, Joubert syndrome, Bardet-Biedl syndrome, and oral-facial-digital syndrome.

The pathogenesis of Caroli disease is unclear, but it is usually related to gene mutations in the PKHD1 gene, which has been localized to the chromosome 6p21.1-p12, and is frequently associated with autosomal recessive polycystic kidney disease (ARPKD).

Clinical manifestations are secondary to bile duct abnormalities and portal hypertension due to portal fibrosis. Diagnosis is generally established through a radiological approach, including ultrasound (US), endoscopic retrograde cholangiopancreatography (ERCP) and/or magnetic resonance imaging (MRI) in order to show bile duct ectasia and irregular, cystic dilation of the large proximal intrahepatic bile ducts. These findings could help to exclude extrahepatic choledochal cysts (type V) (13).

The first line of treatment is medical and prevents complications from cholangitis, portal hypertension (esophageal varices), and barely, liver failure (13-15). In the case of refractory disease, LT may be the only option. The largest series of 140 patients with Caroli disease or syndrome transplanted between 1987 and 2011 reported an excellent OS (16).

\section{Hepatic sinusoidal obstruction syndrome (SOS)}

Hepatic SOS, formerly known as hepatic veno-occlusive disease is a rare disease similar to BCS. In SOS, the occlusion-causing hepatic venous outflow obstruction affects the terminal hepatic venules and hepatic sinusoids. Clinical features are similar to BCS, and patients present right upper quadrant pain, jaundice, and ascites. Hepatomegaly is typical. SOS is often secondary to hematopoietic cell transplantation (HCT) or monoclonal antibody treatment (17-20). Female sex and reduced lung diffusing capacity, along with the use of amphotericin, vancomycin, and acyclovir, are risk factors associated with SOS (19). Diagnosis should be considered in case of patients receiving HCT, and the modified Seattle criteria (19) are a useful tool in diagnosing suspect SOS when 2 or more of the following events are present: bilirubin $>2 \mathrm{mg} / \mathrm{dL}$, hepatomegaly and upper right quadrant pain, or sudden weight gain due to fluid accumulation.

A large variety of pathological findings can be ascertained through US, CT scan, and MRI, but a liver biopsy is mandatory and also enables a differential diagnosis, particularly with BCS. SOS due to tacrolimus has been reported in lung and pancreatic transplantation, but has never been described in LT recipients $(21,22)$.

Patients with SOS are usually frail patients, with poor performance status due to other therapies such as radiotherapy or chemotherapy. In this scenario, the indication and the timing to LT has to be strict (19). So far, there is no evidence concerning LT safety. Only few case reports describe a good outcome, while several other studies show high risks of post-operative complications and graft versus host disease (22-24).

\section{Metabolic diseases}

A large variety of metabolic diseases can lead to liver injury and failure, but LT is not always necessary or recommended. The following section describes the most common metabolic diseases that can require LT.

\section{Alpha-1 antitrypsin deficiency}

Adult patients affected by alpha- 1 antitrypsin deficiency are usually asymptomatic. Only a small portion of this population shows abnormal liver enzyme levels $(25,26)$. A study based on autopsies performed on affected individuals 
showed that $50 \%$ of cases had cirrhosis, which evolve to hepatocarcinoma (HCC) in $28 \%$ of cases (27).

When alpha-1 antitrypsin deficiency is suspected, a genetic test can be helpful when combined with a measurement of the plasma level of alfa-1 antitrypsin (28). In case of end-stage liver failure, LT is the only effective treatment (29), with an excellent 5-year OS and graft survival of $83 \%$ and $77 \%$ being respectively achieved (30).

\section{Hereditary hemochromatosis $(\mathbf{H H})$}

$\mathrm{HH}$ is a metabolic disease related to an excess of hepatic iron. In $4-6 \%$ of patients, it is related to the mutation of C282Y and can lead to liver cirrhosis (30). Therapeutic phlebotomy can help to decelerate the disease, but end-stage liver disease (31) is often inevitable $(32,33)$. Furthermore, studies have shown that $\mathrm{HH}$ increases the risk of HCC development, which occurs predominantly in patients with cirrhosis at the time of diagnosis (34). A high level of iron could be seen in patients with other causes of liver disease, and a combination with $\mathrm{HH}$ is quite rare (34).

This disease represents $0.5-1 \%$ of all LT indications (35), and a small portion of all patients progress to LT. Since the excess of iron in the heart can lead to congestive heart failure, a strictly cardiovascular work-up before LT is mandatory (36).

\section{Polycystic liver disease (PLD)}

The PLD consists of multiple simple cysts in the liver more than $1 \mathrm{~cm}$ in size, with no sign of infection or traumatic origin (37).

PLD can be associated with autosomal dominant polycystic kidney disease (ADPKD, caused by mutations in the PKD1 gene and PKD2 gene) or can be an autosomal dominant PLD (ADPLD, caused by mutations in the PRKCSH gene among others).

PLD is most frequently associated with ADPKD, while ADPLD is less common and occurs in the absence of renal cystic involvement. In patients with ADPKD, the kidney cysts usually precede the liver cysts. This disease is prevalent in females, because the hepatic cystogenesis is sexdependent, at least in the fertile age $(38,39)$.

Pathogenesis seems to be related, at least in most of cases, to ductal plate malformation associated with cilium defects, and cholangiopathy results from abnormalities in the late stages of embryonic liver development. This disease leads to a progressive growth of fluid cysts that gradually may replace liver tissue. With aging, the number of cysts and total liver volume increase, and an annual growth rate of $0.0-3.2 \%$ has been estimated (37-39).

Renal involvement or hepatomegaly are primarily responsible for the following symptoms related to abdominal compression: abdominal pain, abdominal distention, dyspnea, dyspepsia, and complications secondary to portal hypertension or bile duct compression. On rare occasions, PLD can lead to acute symptoms due to cyst hemorrhage, rupture, or infection, but liver failure and death from isolated PLD is extremely unlikely (40). However, due to the slow cyst growth, the vast majority of patients with PLD are asymptomatic. Possible manifestations usually do not appear before 50 to 60 years of age. Female gender, advancing age, and large renal cysts are risk factors for liver cyst growth $(37,39)$.

Few medical treatments are currently available for PLD, but somatostatin analogues like octreotide and mTOR inhibitors have been used with variable success, with an effect that seems more pronounced on renal involvement $(37,40)$. Sclerotherapy, laparoscopic fenestration, and liver resection are usually offered in cases of symptomatic PLD. However, when symptoms are not manageable (abdominal pain, abdominal distension, high risks of cyst complication, low quality of life, malnutrition due to early satiety from gastric compression by enlarged cysts) and/or not responsive to medical and surgical therapy, LT is often the only available option. Of note, in these patients, hepatic function is usually normal and the MELD score system is not informative. Exceptions have to be made for the patient to have an opportunity for transplant and to progress in the waiting list. However, even with exceptions, in UNOS area patients with PLD have a higher risk of mortality or drop out more often than listed patients with HCC (41).

Notwithstanding, data show that patients with progressive PLD might benefit from LT, with a 1 - and 5 -year survival of $93 \%$ and $91 \%$, respectively. When a kidney transplant was needed, simultaneous liver-kidney transplant showed a 1 - and 5 -year survival of $86 \%$ and $80 \%$, respectively. PLD represents $1 \%$ of all indications to LT $(40,41)$.

It is interesting to note that patients transplanted for PLD have a 30 -day morbidity of $41 \%$ and a mortality of $5 \%(39,40)$. These data can be attributed to intraoperative technical issues particularly during the hepatectomy phase: an average cirrhotic transplanted liver is usually $1.1 \mathrm{~kg}$, while polycystic livers usually weigh $6.6 \mathrm{~kg}$, with cases of 14 and $19 \mathrm{~kg}$ being reported $(42,43)$. Studies also suggest that patients transplanted for PLD have higher rates of vascular 
complications, with hepatic artery thrombosis in particular, which is related to a procoagulant state (40).

Considering that even untreated PLD is not associated with high mortality, the risks of surgery have to be carefully evaluated. In this setting, multidisciplinary evaluation of the patient is mandatory (37).

\section{LT in bariatric surgery}

Bariatric surgery may rarely lead to liver failure, especially after jejuno-ileal bypass and biliopancreatic diversion. Protein malnutrition and bacterial overgrowth are the main causes of liver damage following bariatric surgery (44). A recent systematic review analyzed 14 studies reporting 36 patients listed to LT after bariatric surgery. This group comprised cases of jejuno-ileal bypass $(n=16)$, biliopancreatic diversion according to Scopinaro $(n=14)$, duodenal switch $(\mathrm{n}=3)$, biliointestinal bypass $(\mathrm{n}=1)$, long-limb Roux-en-Y gastric bypass $(\mathrm{n}=1)$, and single-anastomosis omega gastric bypass $(n=1)$. Liver failure developed usually within a median of 20 months after surgery, with biliopancreatic diversion being an exception where liver failure appeared with a shorter interval. Data showed that LT might be a viable option in this cohort of patients (45).

\section{Alagille syndrome}

Alagille syndrome is an inherited autosomal dominant multisystemic disease caused by mutation in $7 A G 1$ localized in the chromosome 20p12 (46), characterized by paucity of interlobular bile ducts at the hepatic level.

The largest parts of patients (almost $85 \%$ ) are diagnosed before 6 months of age because of jaundice and failure to thrive, or cardiovascular symptoms. Other typical features are chronic cholestasis (90\%), cardiac anomalies, peripheral pulmonic stenosis (85-91\%), butterfly vertebrae (39-87\%), posterior embryotoxon (prominent Schwalbe line) of the eye (61-88\%), and dysmorphic facies consisting of broad nasal bridge, triangular faces, and deep set eyes (77-95\%) (47-50). In these patients, growth and mental retardation, developmental delay, renal disease, and pancreatic insufficiency can be also present, but to a lesser extent.

Severe liver disease is indeed a major cause of morbidity. Increase in serum levels of bilirubin is the major criterion to perform biliary diversion procedures, and LT can occasionally be considered in patients with intractable pruritus, osteodystrophy, progressive liver synthetic dysfunction, or rarely, variceal bleeding. The consistency of
LT for Alagille syndrome has been shown in a study of 163 patients (51), but ursodeoxycholic acid in a few cases was also demonstrated to be of some help (52).

\section{Neoplastic diseases with possible indication to LT}

\section{Benign liver tumor}

Benign liver tumors are not rare finding in the general population, but they may constitute a rare indication to LT. The three most common types of benign liver tumors are hepatic hemangiomas (HHes), focal nodular hyperplasia (FNH), and hepatocellular adenomas; they rarely require medical or surgical treatment (53). Hepatic hemangioma is the most frequent benign liver tumor. It consists of multiple, large, distorted blood vessels with a single layer of endothelial cell filled with blood and nourished by the hepatic arterial circulation. Usually HHEs manifest as single lesions, but multiple liver lesions also occur (54).

HHes incidence in the general population ranges from $0.4 \%$ to $20 \%$, and is most commonly diagnosed as incidental finding between the ages of 30 and 50 years old, more often in females. HHes with a diameter larger than $10 \mathrm{~cm}$ are defined as giant liver hemangioma (54). HHes are usually asymptomatic, but giant or cavernous HHes, as in cases of PLD, can cause compressive symptoms related to the massive hepatomegaly. Acute complications of HHes are rare, but can be life threatening. A spontaneous or traumatic rupture of a giant HHes is uncommon (1-4\%), but the mortality is elevated (36-39\%); Kasabach-Merritt syndrome (KMS) (giant liver HHes, associated with thrombocytopenia, intravascular coagulation, consumptive coagulopathy) can progress to disseminated intravascular coagulation and multi-organ failure (MOF) (55). In this scenario, treatment and surgery is usually indicated, even if there is no consensus regarding the optimal management: liver resection, enucleation, irradiation, or selective embolization of the feeding hepatic artery. Although LT is rarely performed, it has to be considered in order to prevent HHes complications (55-57). A recent review, reporting 19 cases of LT for giant HHes, suggested LT for non-resectable HHes in patients with imminent lifethreatening complications (especially KMS), an increased risk of malignant transformation, an underlying liver disease, or the presence of severe symptoms (58). FNH and hepatocellular adenomas are not an indication for LT by themselves, but they are if associated with another liver disease, which was the indication for LT $(59,60)$. 


\section{$C C A$}

CCA is a malignant tumor with features of biliary differentiation. It is rare in the Western world, occurring in $0.5-2$ individuals per 100,000 per year, but the disease has a much higher incidence in the Asian population. Despite this, CCA it is the second most common primary liver cancer after HCC, and the incidence of the disease is especially high in patients with PSC (61).

CCA can be classified according to its locations on the biliary tree, and requires different diagnostic and treatment approaches: intrahepatic (iCCA), distal (dCCA), and perihilar (pCCA) cholangiocarcinoma. iCCA and $\mathrm{dCCA}$, as a result of poor results related to LT, are still contraindications to LT, while pCCA is a potential indication to LT (62). In pCCA, surgical resection with a negative margin (R0) is the most favorable prognostic factor, but unfortunately, it is only possible in $25-40 \%$ of the patients and has a 5 -year survival rate of $40 \%(63,64)$.

Given this setting, LT could offer better survival in patients with an unresectable pCCA at risk of R1/R2 or of post-hepatectomy liver failure due to inadequate future liver remnant $(65,66)$. The first LT experience for pCCA presented poor results, with a 3 - and 5-year survival ranging from $30 \%$ to $23 \%$ respectively, with a high rate of recurrence (67-69). In 1993, a Mayo Clinic protocol for pCCA was introduced, consisting of external beam radiation therapy (45 Gy in 30 fractions, 1.5 Gy twice daily), brachytherapy (20 Gy at $1 \mathrm{~cm}$ for approximately 20-25 hours), and capecitabine until the time of LT. Before LT, laparoscopic abdominal staging is necessary in order to exclude metastatic disease and to asses lymph nodes status (66). The first positive results, showing an OS after LT at 5 years of $74 \%$, were reported in multicentric studies (70). This advantage in term of OS was also confirmed for unresectable hilar CCA and hilar CCA arising in the setting of PSC. PSC is a rare disease (prevalence less than 50 per 100,000 ) and it is a well establish indication to LT in patients with intractable pruritus, recurrent bacterial cholangitis, or poor liver function. Ten-twenty percent of patients with PSC develop CCA, and in this setting LT has been shown to provide an important therapeutic tool (66).

Although the Mayo Clinic protocol represented indeed a breakthrough, some aspects are hitherto under debate. Data are still insufficient to determine whether the results may be biased by the high selection of the patients due to the strict protocol, or by the efficacy of the pre-LT therapy itself. Furthermore, considering that mass biopsy prior to LT is at high risk of seeding, one series reported a $15 \%$ liver with no sign of cancer after LT, suggesting that the initial diagnosis of pCCA was not correct (71). However, LT showed a better 5 -year survival compared to patients who received liver resection (18\% vs. 64\%) (72). How to prioritize LT for pCCA is still matter of controversy. Recently, hilar CCA arising in

the setting of PSC has been established to be correlated with good outcome after LT, and MELD score exception has been proposed to prioritize the patients in the waiting list (73).

\section{Epithelioid hemangioendothelioma (EHE)}

EHE is a rare vascular tumor originating from vascular endothelial and mesenchymal epithelioid cells. It is associated with a low-intermediate grade of malignity, between benign hemangioma and malignant angiosarcoma, with a low risk of metastatic disease (74).

Primary malign EHE is a very rare tumor (incidence less than $1 / 1$ million), predominantly presenting in women ( $61 \%$ of cases) between 30 and 40 years of age (75).

Most of the patients are asymptomatic, and the diagnosis is accidental. Symptoms are related to the growing of the tumor mass, mostly consisted of stroma. Abdominal pain, portal hypertension, symptoms secondary to abdominal mass, and liver failure can be present. Laboratory studies and imaging studies can suggest the diagnosis of $\mathrm{EHE}$, but the final diagnosis is made histologically with immunohistochemistry (76).

In EHE, disease history has exhibited a $4.5 \%$ (75) patient survival rate, but systemic chemotherapy has shown no OS benefit. Liver resection and other therapeutic options such as ablative techniques, transarterial chemoembolization (TACE), and radiation therapy are frequently the first treatment choice and have yielded excellent results (5-year OS of $75 \%$ ), but they are often not feasible due to the multinodular and bilobar presentation of the disease. In this setting, LT seems to be the most favorable choice of treatment, even if extrahepatic disease is present, and has achieved a low rate of recurrence and a 5 -year OS following LT ranging from $54 \%$ to $83 \%$ (77).

Studies performed by the European Liver and Intestine Transplant Association (ELITA) and ELTR were the first based on a large cohort and long follow-up, and proved that LT is a viable treatment option. These studies examined a total of 149 patients transplanted for EHE, reporting a 10year disease-free survival (DFS) of $73 \%$ with an 10 -year OS 
of 77\% (78-80). Meanwhile, the UNOS registry reported a 5 -year survival rate of $64 \%$ in 110 patients transplanted for EHE (80). Based on these studies, it is difficult to estimate the risk of progression from EHE to hemangiosarcoma after LT. However, data showed that patients transplanted for hemangiosarcoma showed a lower overall survival (less than 2 years) than patients transplanted for EHE (78-80).

Recently, the therapeutic algorithm for EHE based on risk of recurrence and extrahepatic disease localization was proposed, allowing for a better management of the disease $(78,81)$.

\section{Neuroendocrine tumors (NETs)}

NETs are rare tumors, with an annual incidence of 5 cases per 100,000 people (82). They are produced by cells of the neuroendocrine system found throughout the digestive tract, and their biological behavior can be heterogenous. Usually this disease is diagnosed when already metastasized, predominantly to the liver (46-93\%) (83). Intestinal and pancreatic NETs are the most common source of liver metastasis. NETs are slow-growing tumors, but the involvement of the liver heavily impinges on the OS. For instance, a $13-54 \%$ rate of 5 -year $\mathrm{OS}$ in the presence of liver metastases was reported compared to the OS of $75-99 \%$ in non-metastatic NETs (84). Liver resection proved not to be very effective for improving the OS, making LT in highly selected patients with unresectable liver metastasis NETs as the only potential curative treatment. The presence of extrahepatic disease (previous peritoneal carcinomatosis and distant lymph nodes) is an absolute contraindication to LT; in this scenario, a staging laparoscopy might be helpful before LT.

LT for liver metastatic NETs is usually indicated in the case of unresectable liver metastases not approachable by other medical or surgical treatments (so-called oncological indication) or unresectable liver metastases with refractory symptoms (hormonal and tumor bulk indications).

Studies have reported a 5-year OS of 47-97\% and disease-free survival rates of $32-87 \%$ after LT. A recent review reported an overall post-LT recurrence ranging from $31.3 \%$ to $56.8 \%$, with a $1-, 3$-, and 5 -year OS of $89 \%, 69 \%$, and $63 \%$, respectively (85). More than $50 \%$ of liver involvement, high $\mathrm{Ki}-67$ index, and pancreatic primary localization were associated with worse long-term survival after LT (86). However, lacking long-term results and prospective trials, LT for liver metastatic NETs is still highly controversial. Milan-NET criteria $(86,87)$, UNOS guidelines, or the European Neuroendocrine Tumor
Society (ENETS) guidelines (88) have tried to standardize the indication to LT, but patient selection criteria are still poorly defined (Table 4) (89), and whether stable disease or progressive disease is an indication to LT is still a matter of debate.

\section{Colo-rectal liver metastases}

Colorectal cancer (CRC) is the third most common tumor worldwide and liver metastases develop in 20-30\% of cases, strongly affecting the long-term outcome of patients (90). The current gold standard treatment for colorectal liver metastasis (CRLMs) is represented by local treatment based on liver resection, and is associated with systemic chemotherapy, yielding a 5 -year survival of $31-58 \%$. However, liver resection is feasible in only $20 \%$ of the patients, and palliative chemotherapy is associated with poor outcome (5-year OS of 10\%) (91). In this setting, recent studies and trials are showing that, in highly select patients, LT for unresectable CRLM is a viable option with good long-term outcomes. The SECA-II study, a randomized controlled clinical trial of 15 patients transplanted for CRLM selected according to strict criteria, showed an OS at 1,3, and 5 years of $100 \%, 83 \%$, and $83 \%$, respectively, with a median follow-up of 36 months (92). The best option between transplantation and other treatments (chemotherapy) will depend on the results of other ongoing trials including the TRANSMET and SECA-III trials, along with the Partial Liver Segment 2/3 Transplantation Study (Table 5).

\section{Conclusions}

LT is the standard treatment for patients affected by liver failure that mostly results from liver cirrhosis. However, in the last few years, LT for rare diseases has been receiving considerable interest. It represents less than $1 \%$ of all indications to LT, including non-hepatocellular malignancies, vascular disorders, and metabolic and congenital liver disorders. Knowing the nonstandard indications for LT and providing an early referral to a transplant center could improve the overall survival and the quality of life in these patients.

On the other hand, rare indications to LT from non-rare diseases, including those of CRLM or cholangiocarcinoma, could have the potential to become future common indications due to the crisis of the conventional indications to LT (such as HCV-related cirrhosis), the expanded criteria for marginal donors, or an increased use of living donor LT 
Table 4 LT in patients with metastatic NETs: Milan, UNOS, and ENETS Criteria

\begin{tabular}{llll}
\hline Inclusion criteria & Milan Criteria & UNOS Criteria & ENETS Criteria \\
\hline Histology & $\begin{array}{l}\text { Confirmed histology of low-grade NET with or } \\
\text { without the presence of the syndrome }\end{array}$ & $\begin{array}{l}\text { Confirmed histology of } \\
\text { low-grade NET }\end{array}$ & $\begin{array}{l}\text { Confirmed histology of } \\
\text { low-grade NET }\end{array}$ \\
Primary tumor site & $\begin{array}{l}\text { Primary tumor drained by the portal system } \\
\text { already removed with a curative resection }\end{array}$ & $\begin{array}{l}\text { Primary tumor drained by } \\
\text { the portal system }\end{array}$ & N/A \\
Metastatic involvement & Metastatic diffusion to $<50 \%$ of the total liver \\
volume & $\begin{array}{l}\text { Metastatic diffusion to }<50 \% \text { N/A } \\
\text { of the total liver volume }\end{array}$ & N/A \\
Disease stability & Stable disease/response to therapies for at least \\
& 6 months prior to transplant consideration & of at least 6 months & N/A \\
Age & $<60$ (relative criteria) & $<60$ & Exclusion of extrahepatic disease \\
Others & - & - & Low bilirubin \\
\hline
\end{tabular}

Table 5 Comparison between studies on LT for CRLM

\begin{tabular}{|c|c|c|c|c|c|}
\hline Variable & SECA II study (92) & $\begin{array}{l}\text { Compagnons } \\
\text { Hépato-Biliaires } \\
\text { (93) }\end{array}$ & $\begin{array}{l}\text { Toronto } \\
\text { (NCT02864485) }\end{array}$ & TRANSMET & Oslo (NCT02215889) \\
\hline Type of study & Prospective study & $\begin{array}{l}\text { Retrospective } \\
\text { cohort study }\end{array}$ & $\begin{array}{l}\text { Prospective } \\
\text { cohort }\end{array}$ & Prospective RCT & Prospective \\
\hline \multicolumn{2}{|c|}{ Number of participants 15} & 12 & Ongoing & Ongoing & Ongoing \\
\hline \multirow[t]{4}{*}{ Methods } & $\begin{array}{l}\text { Whole liver from } \\
\text { deceased donor }\end{array}$ & $\begin{array}{l}\text { Whole liver from } \\
\text { deceased/domino } \\
\text { donor }\end{array}$ & Living donor LT & $\begin{array}{l}\text { Whole liver from } \\
\text { deceased donor }\end{array}$ & Living donor segment $2 / 3$ \\
\hline & $\begin{array}{l}\text { Nonresectable } \\
\text { liver-only }\end{array}$ & $\begin{array}{l}\text { Prevalent } \\
\text { synchronous } \\
\text { metastases }\end{array}$ & $\begin{array}{l}\text { Nonresectable } \\
\text { liver-only }\end{array}$ & $\begin{array}{l}\text { Nonresectable } \\
\text { liver-only }\end{array}$ & Nonresectable liver-only \\
\hline & $\begin{array}{l}\text { Response to } \\
\text { chemotherapy }\end{array}$ & $\begin{array}{l}\text { Response to } \\
\text { chemotherapy }\end{array}$ & $\begin{array}{l}\text { Response to } \\
\text { chemotherapy }\end{array}$ & $\begin{array}{l}\text { Response to } \\
\text { chemotherapy }\end{array}$ & - \\
\hline & - & - & - & $\begin{array}{l}\text { Multicenter randomized } \\
\text { parallel group open } \\
\text { trial comparing; OS CT } \\
\text { followed by LT vs. CT } \\
\text { alone }\end{array}$ & $\begin{array}{l}\text { Stage 1: S2-S3 removed and } \\
\text { liver donor implanted; Stage 2: } \\
\text { After growth of donor segments, } \\
\text { the remaining liver segments of } \\
\text { the recipient were removed }\end{array}$ \\
\hline \multirow[t]{3}{*}{ Inclusion criteria } & $\begin{array}{l}\text { Histologically } \\
\text { verified } \\
\text { adenocarcinoma in } \\
\text { the colon or rectum }\end{array}$ & - & $\begin{array}{l}\text { Primary CRC } \\
\text { with tumor } \\
\text { stage }<\mathrm{T} 4 \mathrm{a}\end{array}$ & $\begin{array}{l}\text { Histologically verified } \\
\text { adenocarcinoma in the } \\
\text { colon or rectum }\end{array}$ & $\begin{array}{l}\text { Histologically verified } \\
\text { adenocarcinoma in the colon or } \\
\text { rectum }\end{array}$ \\
\hline & $\begin{array}{l}\text { No signs of } \\
\text { extrahepatic } \\
\text { metastatic disease } \\
\text { or local recurrence }\end{array}$ & - & $\begin{array}{l}\text { No signs of } \\
\text { extrahepatic } \\
\text { metastatic } \\
\text { disease or local } \\
\text { recurrence }\end{array}$ & $\begin{array}{l}\text { No signs of } \\
\text { extrahepatic metastatic } \\
\text { disease or local } \\
\text { recurrence }\end{array}$ & $\begin{array}{l}\text { No signs of extrahepatic } \\
\text { metastatic disease or local } \\
\text { recurrence except in 1-3 } \\
\text { resectable lung lesions; all } \\
<15 \mathrm{~mm}\end{array}$ \\
\hline & ECOG 0 or 1 & - & ECOG 0 or 1 & ECOG 0 or 1 & ECOG 0 or 1 \\
\hline
\end{tabular}

Table 5 (continued) 
Table 5 (continued)

\begin{tabular}{|c|c|c|c|c|c|}
\hline Variable & SECA II study (92) & $\begin{array}{l}\text { Compagnons } \\
\text { Hépato-Biliaires } \\
\text { (93) }\end{array}$ & $\begin{array}{l}\text { Toronto } \\
\text { (NCT02864485) }\end{array}$ & TRANSMET & Oslo (NCT02215889) \\
\hline & $\begin{array}{l}\text { Resected primary } \\
\text { tumor with } \\
\text { adequate resection } \\
\text { margins }\end{array}$ & - & $\begin{array}{l}\text { CT for } \\
>3 \text { months }\end{array}$ & $\begin{array}{l}\text { Resected primary } \\
\text { tumor with adequate } \\
\text { resection margins }\end{array}$ & - \\
\hline & $\begin{array}{l}\text { Received first-line } \\
\text { treatment }\end{array}$ & - & $\begin{array}{l}\text { Time from } \\
\text { primary CRC } \\
\text { resection to } \\
\text { transplant } \\
>6 \text { months }\end{array}$ & $\begin{array}{l}\text { Eligible for both } \\
\text { treatment groups }\end{array}$ & - \\
\hline & $\begin{array}{l}\text { Time criteria: } \\
1 \text { year from } \\
\text { diagnosis to listing } \\
\text { for } L T\end{array}$ & - & $\begin{array}{l}\text { Stable or } \\
\text { decreasing CEA } \\
\text { values }\end{array}$ & $\begin{array}{l}\text { CEA }<80 \mathrm{mg} / \mathrm{L} \text { or a } \\
\text { decrease }>50 \% \text { of the } \\
\text { highest value }\end{array}$ & - \\
\hline & - & - & BRAF negative & BRAF negative & - \\
\hline Results & & & N/A & $\mathrm{N} / \mathrm{A}$ & $\mathrm{N} / \mathrm{A}$ \\
\hline Median FU & 36 months & 26 months & & & \\
\hline 1-year OS & $100 \%$ & $83 \%$ & & & \\
\hline 3-year OS & $83 \%$ & $62 \%$ & & & \\
\hline 5-year OS & $83 \%$ & $50 \%$ & & & \\
\hline 1-year DSF & $53 \%$ & $56 \%$ & & & \\
\hline 3-year DSF & $44 \%$ & $38 \%$ & & & \\
\hline 5-year DSF & $35 \%$ & $38 \%$ & & & \\
\hline Recurrence & > Pulmonary & > Pulmonary & & & \\
\hline
\end{tabular}

$\mathrm{N} / \mathrm{A}$, not applicable.

for such indications.

\section{Acknowledgments}

Funding: None.

\section{Footnote}

Provenance and Peer Review: This article was commissioned by the Guest Editors (Luca Fabris and Mario Strazzabosco) for the series "Recent Advances in Rare Liver Diseases" published in Translational Gastroenterology and Hepatology. The article was sent for external peer review organized by the Guest Editors and the editorial office.

Conflicts of Interest: All authors have completed the ICMJE uniform disclosure form (available at http://dx.doi. org/10.21037/tgh-19-282). The series "Recent Advances in Rare Liver Diseases" was commissioned by the editorial office without any funding or sponsorship. Alessandro Vitale serves as an unpaid editorial board member of Translational Gastroenterology and Hepatology from Jan 2020 to Dec 2021. The authors have no other conflicts of interest to declare.

Ethical Statement: The authors are accountable for all aspects of the work in ensuring that questions related to the accuracy or integrity of any part of the work are appropriately investigated and resolved.

Open Access Statement: This is an Open Access article distributed in accordance with the Creative Commons 
Attribution-NonCommercial-NoDerivs 4.0 International License (CC BY-NC-ND 4.0), which permits the noncommercial replication and distribution of the article with the strict proviso that no changes or edits are made and the original work is properly cited (including links to both the formal publication through the relevant DOI and the license). See: https://creativecommons.org/licenses/by-nc-nd/4.0/.

\section{References}

1. Adam R, Karam V, Cailliez V, et al 2018 Annual Report of the European Liver Transplant Registry (ELTR) 50 -year evolution of liver transplantation. Transpl Int 2018;31:1293-317.

2. Kim WR, Lake JR, Smith JM, et al. OPTN/SRTR 2016 Annual Data Report: Liver. Am J Transplant 2018;18 Suppl 1:172-253.

3. Hagness M, Foss A, Line PD, et al. Liver transplantation for nonresectable liver metastases from colorectal cancer. Ann Surg 2013;257:800-6.

4. Kim WR, Lake JR, Smith JM, et al. OPTN/SRTR 2017 Annual Data Report: Liver. Am J Transplant 2019;19 Suppl 2:184-283.

5. Cholankeril G, Wong RJ, Hu M, et al. Liver Transplantation for Nonalcoholic Steatohepatitis in the US: Temporal Trends and Outcomes. Dig Dis Sci 2017;62:2915-22.

6. Menon KV, Shah V, Kamath PS. The Budd-Chiari syndrome. N Engl J Med 2004;350:578-85.

7. Ferral H, Behrens G, Lopera J. Budd-Chiari syndrome. AJR Am J Roentgenol 2012;199:737-45.

8. Plessier A, Valla DC. Budd-Chiari syndrome. Semin Liver Dis 2008;28:259-69.

9. Mentha G, Giostra E, Majno PE, et al. Liver transplantation for Budd-Chiari syndrome: A European study on 248 patients from 51 centres. J Hepatol 2006;44:520-8.

10. Segev DL, Nguyen GC, Locke JE, et al. Twenty years of liver transplantation for Budd-Chiari syndrome: a national registry analysis. Liver Transpl 2007;13:1285-94.

11. Ulrich F, Pratschke J, Neumann U, et al. Eighteen years of liver transplantation experience in patients with advanced Budd-Chiari syndrome. Liver Transpl 2008;14:144-50.

12. Summerfield JA, Nagafuchi Y, Sherlock S, et al. Hepatobiliary fibropolycystic diseases. A clinical and histological review of 51 patients. J Hepatol 1986;2:141-56.

13. Kassahun WT, Kahn T, Wittekind C, et al. Caroli's disease: liver resection and liver transplantation.
Experience in 33 patients. Surgery 2005;138:888-98.

14. Waechter FL, Sampaio JA, Pinto RD, et al. The role of liver transplantation in patients with Caroli's disease. Hepatogastroenterology 2001;48:672-4.

15. Habib S, Shakil O, Couto OF, et al. Caroli's disease and orthotopic liver transplantation. Liver Transpl 2006;12:416-21.

16. Harring TR, Nguyen NT, Liu H, et al. Caroli disease patients have excellent survival after liver transplant. J Surg Res 2012;177:365-72.

17. McKoy JM, Angelotta C, Bennett CL, et al. Gemtuzumab ozogamicin-associated sinusoidal obstructive syndrome (SOS): an overview from the research on adverse drug events and reports (RADAR) project. Leuk Res 2007;31:599-604.

18. Wadleigh M, Richardson PG, Zahrieh D, et al. Prior gemtuzumab ozogamicin exposure significantly increases the risk of veno-occlusive disease in patients who undergo myeloablative allogeneic stem cell transplantation. Blood 2003;102:1578-82.

19. McDonald GB, Hinds MS, Fisher LD, et al. Venoocclusive disease of the liver and multiorgan failure after bone marrow transplantation: a cohort study of 355 patients. Ann Intern Med 1993;118:255-67.

20. Carreras E, Bertz H, Arcese W, et al. Incidence and outcome of hepatic veno-occlusive disease after blood or marrow transplantation: a prospective cohort study of the European Group for Blood and Marrow Transplantation. European Group for Blood and Marrow Transplantation Chronic Leukemia Working Party. Blood 1998;92:3599-604.

21. Shah S, Budev M, Blazey H, et al. Hepatic veno-occlusive disease due to tacrolimus in a single-lung transplant patient. Eur Respir J 2006;27:1066-8.

22. Wang SE, Shyr YM, Lee RC. Hepatic veno-occlusive disease related to tacrolimus after pancreas transplantation. J Chin Med Assoc 2013;76:358-60.

23. Valla DC, Cazals-Hatem D. Sinusoidal obstruction syndrome. Clin Res Hepatol Gastroenterol 2016;40:378-85.

24. Membreno FE, Ortiz J, Foster PF, et al. Liver transplantation for sinusoidal obstructive syndrome (veno-occlusive disease): case report with review of the literature and the UNOS database. Clin Transplant 2008;22:397-404.

25. Nelson DR, Teckman J, Di Bisceglie AM, et al. Diagnosis and management of patients with alpha1antitrypsin (A1AT) deficiency. Clin Gastroenterol Hepatol 2012;10:575-80. 
26. American Thoracic S, European Respiratory S. American Thoracic Society/European Respiratory Society statement: standards for the diagnosis and management of individuals with alpha-1 antitrypsin deficiency. Am J Respir Crit Care Med 2003;168:818-900.

27. Elzouki AN, Eriksson S. Risk of hepatobiliary disease in adults with severe alpha 1-antitrypsin deficiency ( $\mathrm{PiZZ):} \mathrm{is} \mathrm{chronic} \mathrm{viral} \mathrm{hepatitis} \mathrm{B}$ or $\mathrm{C}$ an additional risk factor for cirrhosis and hepatocellular carcinoma? Eur J Gastroenterol Hepatol 1996;8:989-94.

28. Silverman EK, Sandhaus RA. Clinical practice. Alpha1antitrypsin deficiency. N Engl J Med 2009;360:2749-57.

29. Kemmer N, Kaiser T, Zacharias V, et al. Alpha-1antitrypsin deficiency: outcomes after liver transplantation. Transplant Proc 2008;40:1492-4.

30. Olynyk JK, Cullen DJ, Aquilia S, et al. A population-based study of the clinical expression of the hemochromatosis gene. N Engl J Med 1999;341:718-24.

31. Bralet MP, Regimbeau JM, Pineau P, et al. Hepatocellular carcinoma occurring in nonfibrotic liver: epidemiologic and histopathologic analysis of 80 French cases. Hepatology 2000;32:200-4.

32. Elmberg M, Hultcrantz R, Ekbom A, et al. Cancer risk in patients with hereditary hemochromatosis and in their first-degree relatives. Gastroenterology 2003;125:1733-41.

33. Fracanzani AL, Conte D, Fraquelli M, et al. Increased cancer risk in a cohort of 230 patients with hereditary hemochromatosis in comparison to matched control patients with non-iron-related chronic liver disease. Hepatology 2001;33:647-51.

34. Yu L, Ioannou GN. Survival of liver transplant recipients with hemochromatosis in the United States. Gastroenterology 2007;133:489-95.

35. Kowdley KV, Brandhagen DJ, Gish RG, et al. Survival after liver transplantation in patients with hepatic iron overload: the national hemochromatosis transplant registry. Gastroenterology 2005;129:494-503.

36. Dar FS, Faraj W, Zaman MB, et al. Outcome of liver transplantation in hereditary hemochromatosis. Transpl Int 2009;22:717-24.

37. Wong MY, McCaughan GW, Strasser SI. An update on the pathophysiology and management of polycystic liver disease. Expert Rev Gastroenterol Hepatol 2017;11:569-81.

38. Cnossen WR, Drenth JP. Polycystic liver disease: an overview of pathogenesis, clinical manifestations and management. Orphanet J Rare Dis 2014;9:69.

39. Masyuk TV, Masyuk AI, LaRusso NF. Therapeutic Targets in Polycystic Liver Disease. Curr Drug Targets
2017;18:950-7.

40. Chandok N. Polycystic liver disease: a clinical review. Ann Hepatol 2012;11:819-26.

41. Van Keimpema L, De Koning DB, Van Hoek B, et al. Patients with isolated polycystic liver disease referred to liver centres: clinical characterization of 137 cases. Liver Int 2011;31:92-8.

42. Serrano Rodriguez P, Barritt AI, Gerber DA, et al. Liver Transplant for Unusually Large Polycystic Liver Disease: Challenges and Pitfalls. Case Rep Transplant 2018;2018:4863187.

43. Gringeri E, D'Amico FE, Bassi D, et al. Liver transplantation for massive hepatomegaly due to polycystic liver disease: an extreme case. Transplant Proc 2012;44:2038-40.

44. Markowitz JS, Seu P, Goss JA, et al. Liver transplantation for decompensated cirrhosis after jejunoileal bypass: a strategy for management. Transplantation 1998;65:570-2.

45. Addeo P, Cesaretti M, Anty R, et al. Liver transplantation for bariatric surgery-related liver failure: a systematic review of a rare condition. Surg Obes Relat Dis 2019;15:1394-401.

46. Oda T, Elkahloun AG, Meltzer PS, Chandrasekharappa

SC. Identification and cloning of the human homolog (JAG1) of the rat Jagged1 gene from the Alagille syndrome critical region at 20p12. Genomics 1997;43:376.

47. Alagille D, Estrada A, Hadchouel M, et al. Syndromic paucity of interlobular bile ducts (Alagille syndrome or arteriohepatic dysplasia): review of 80 cases. J Pediatr 1987;110:195.

48. Alagille D. Alagille syndrome today. Clin Invest Med 1996;19:325.

49. Emerick KM, Rand EB, Goldmuntz E, et al. Features of Alagille syndrome in 92 patients: frequency and relation to prognosis. Hepatology 1999;29:822.

50. Subramaniam P, Knisely A, Portmann B, et al. Diagnosis of Alagille syndrome-25 years of experience at King's College Hospital. J Pediatr Gastroenterol Nutr 2011;52:84.

51. Lykavieris P, Hadchouel M, Chardot C, Bernard O. Outcome of liver disease in children with Alagille syndrome: a study of 163 patients. Gut 2001;49:431.

52. Gottrand F, Clavey V, Fruchart JC, Farriaux JP. Lipoprotein pattern and plasma lecithin cholesterol acyl transferase activity in children with Alagille syndrome. Atherosclerosis 1995;115:233.

53. Fodor M, Primavesi F, Braunwarth E, et al. Indications for liver surgery in benign tumours. Eur Surg 2018;50:125-31.

54. Bajenaru N, Balaban V, Savulescu F, et al. Hepatic 
hemangioma -review. J Med Life 2015;8 Spec Issue:4-11.

55. Hoekstra LT, Bieze M, Erdogan D, et al. Management of giant liver hemangiomas: an update. Expert Rev Gastroenterol Hepatol 2013;7:263-8.

56. Wang LJ, Zhang YM, Deng YL, et al. Liver transplantation for benign liver tumor: six cases report and literature review. Zhonghua Yi Xue Za Zhi 2016;96:2091-3.

57. Zhang W, Huang ZY, Ke CS, et al. Surgical Treatment of Giant Liver Hemangioma Larger Than $10 \mathrm{~cm}$ : A Single Center's Experience With 86 Patients. Medicine (Baltimore) 2015;94:e1420.

58. Lee JH, Yoon CJ, Kim YH, et al. Living-donor liver transplantation for giant hepatic hemangioma with diffuse hemangiomatosis in an adult: a case report. Clin Mol Hepatol 2018;24:163-8.

59. Merli L, Grimaldi C, Monti L, et al. Liver transplantation for refractory severe pruritus related to widespread multifocal hepatic focal nodular hyperplasia (FNH) in a child: case report and review of literature. Pediatr Transplant 2012;16:E265-8.

60. Tepetes K, Selby R, Webb M, et al. Orthotopic liver transplantation for benign hepatic neoplasms. Arch Surg 1995;130:153-6.

61. Sharma P, Yadav S. Demographics, tumor characteristics, treatment, and survival of patients with Klatskin tumors. Ann Gastroenterol 2018;31:231-6.

62. Goldaracena N, Gorgen A, Sapisochin G. Current status of liver transplantation for cholangiocarcinoma. Liver Transpl 2018;24:294-303.

63. Jarnagin WR, Fong Y, DeMatteo RP, et al. Staging, resectability, and outcome in 225 patients with hilar cholangiocarcinoma. Ann Surg 2001;234:507-17; discussion 517-9.

64. DeOliveira ML, Cunningham SC, Cameron JL, et al. Cholangiocarcinoma: thirty-one-year experience with 564 patients at a single institution. Ann Surg 2007;245:755-62.

65. Cillo U, Fondevila C, Donadon M, et al. Surgery for cholangiocarcinoma. Liver Int 2019;39 Suppl 1:143-55.

66. Heimbach JK, Gores GJ, Haddock MG, et al. Liver transplantation for unresectable perihilar cholangiocarcinoma. Semin Liver Dis 2004;24:201-7.

67. Meyer CG, Penn I, James L. Liver transplantation for cholangiocarcinoma: results in 207 patients. Transplantation 2000;69:1633-7.

68. Robles R, Figueras J, Turrion VS, et al. Spanish experience in liver transplantation for hilar and peripheral cholangiocarcinoma. Ann Surg 2004;239:265-71.
69. Seehofer D, Thelen A, Neumann UP, et al. Extended bile duct resection and [corrected] liver and transplantation in patients with hilar cholangiocarcinoma: long-term results. Liver Transpl 2009; 15:1499-507.

70. Darwish Murad S, Kim WR, Harnois DM, et al. Efficacy of neoadjuvant chemoradiation, followed by liver transplantation, for perihilar cholangiocarcinoma at $12 \mathrm{US}$ centers. Gastroenterology 2012;143:88-98 e3; quiz e14.

71. Rosen CB, Darwish Murad S, Heimbach JK, et al. Neoadjuvant therapy and liver transplantation for hilar cholangiocarcinoma: is pretreatment pathological confirmation of diagnosis necessary? J Am Coll Surg 2012;215:31-8; discussion 38-40.

72. Ethun CG, Lopez-Aguiar AG, Anderson DJ, et al. Transplantation Versus Resection for Hilar Cholangiocarcinoma: An Argument for Shifting Treatment Paradigms for Resectable Disease. Ann Surg 2018;267:797-805.

73. Cillo U, Burra P, Mazzaferro V, et al. A Multistep, Consensus-Based Approach to Organ Allocation in Liver Transplantation: Toward a "Blended Principle Model". Am J Transplant 2015;15:2552-61.

74. Haberal Reyhan N. Liver Transplant for Nonhepatocellular Carcinoma Malignancy. Exp Clin Transplant 2017;15:69-73.

75. Mehrabi A, Kashfi A, Fonouni H, et al. Primary malignant hepatic epithelioid hemangioendothelioma: a comprehensive review of the literature with emphasis on the surgical therapy. Cancer 2006;107:2108-21.

76. Studer LL, Selby DM. Hepatic Epithelioid Hemangioendothelioma. Arch Pathol Lab Med 2018;142:263-7.

77. Lazăr DC, Avram MF, Romoşan I, et al. Malignant hepatic vascular tumors in adults: Characteristics, diagnostic difficulties and current management. World J Clin Oncol 2019;10:110-35.

78. Lai Q, Feys E, Karam V, et al. Hepatic Epithelioid Hemangioendothelioma and Adult Liver Transplantation: Proposal for a Prognostic Score Based on the Analysis of the ELTR-ELITA Registry. Transplantation 2017;101:555-64.

79. Lerut JP, Weber M, Orlando G, et al. Vascular and rare liver tumors: a good indication for liver transplantation? J Hepatol 2007;47:466-75.

80. Rodriguez JA, Becker NS, O'Mahony CA, et al. Longterm outcomes following liver transplantation for hepatic hemangioendothelioma: the UNOS experience from 1987 to 2005. J Gastrointest Surg 2008;12:110-6. 
81. Lerut J, Iesari S. Vascular tumours of the liver: a particular story. Transl Gastroenterol Hepatol 2018;3:62.

82. Frilling A, Clift AK. Surgical Approaches to the Management of Neuroendocrine Liver Metastases. Endocrinol Metab Clin North Am 2018;47:627-43.

83. Yao JC, Hassan M, Phan A, et al. One hundred years after "carcinoid": epidemiology of and prognostic factors for neuroendocrine tumors in 35,825 cases in the United States. J Clin Oncol 2008;26:3063-72.

84. Lim C, Lahat E, Osseis M, et al. Liver Transplantation for Neuroendocrine Tumors: What Have We Learned? Semin Liver Dis 2018;38:351-6.

85. Chan MY, Ma KW, Chan A. Surgical management of neuroendocrine tumor-associated liver metastases: a review. Gland Surg 2018;7:28-35.

86. Moris D, Tsilimigras DI, Ntanasis-Stathopoulos I, et al. Liver transplantation in patients with liver metastases from neuroendocrine tumors: A systematic review. Surgery 2017;162:525-36.

87. Mazzaferro V, Sposito C, Coppa J, et al. The Long-Term Benefit of Liver Transplantation for Hepatic Metastases From Neuroendocrine Tumors. Am J Transplant 2016;16:2892-902.

\section{doi: $10.21037 /$ tgh-19-282}

Cite this article as: Finotti M, Auricchio P, Vitale A, Gringeri E, Cillo U. Liver transplantation for rare liver diseases and rare indications for liver transplant. Transl Gastroenterol Hepatol 2021;6:27.
88. Delle Fave G, O'Toole D, Sundin A, et al. ENETS Consensus Guidelines Update for Gastroduodenal Neuroendocrine Neoplasms. Neuroendocrinology 2016;103:119-24.

89. Shimata K, Sugawara Y, Hibi T. Liver transplantation for unresectable pancreatic neuroendocrine tumors with liver metastases in an era of transplant oncology. Gland Surg 2018;7:42-6.

90. Cronin KA, Lake AJ, Scott S, et al. Annual Report to the Nation on the Status of Cancer, part I: National cancer statistics. Cancer 2018;124:2785-800.

91. NCCN Clinical Practice Guidelines in Oncology (NCCN Guidelines®) for Colorectal Cancer Screening. Version 2.2019. Available online: https://www.nccn.org/about/ news/ebulletin/ebulletindetail.aspx? ebulletinid $=3678$

92. Dueland S, Syversveen T, Solheim JM, et al. Survival Following Liver Transplantation for Patients With Nonresectable Liver-only Colorectal Metastases. Ann Surg 2020;271:212-8.

93. Toso C, Pinto Marques H, Andres A, et al. Liver transplantation for colorectal liver metastasis: Survival without recurrence can be achieved. Liver Transpl 2017;23:1073-6. 